\title{
Announcing the launching of the new journal Public Health and Toxicology
}

\author{
Aristidis M. Tsatsakis ${ }^{1}$, Alexander I. Vardavas ${ }^{1}$
}

AFFILIATION

1 Laboratory of Toxicology, Medical School, University of Crete, Heraklion, Greece

CORRESPONDENCE TO

Aristidis M. Tsatsakis. Laboratory of Toxicology, Medical School, University of Crete, GR-71003, Heraklion, Crete, Greece. E-mail: tsatsaka@uoc.gr ORCID ID: https://orcid.org/0000-0003-3824-2462

KEYWORDS

editorial, public health toxicology

Received: 19 May 2021, Accepted: 21 May 2021

Public Health Toxicol 2021;1(1):2

https://doi.org/10.18332/pht/137797

We are proud to announce the creation of the new journal Public Health and Toxicology.

Public Health and Toxicology is a new double-blind peer-reviewed, open access, online journal that welcomes integrated epidemiological, clinical, animal and cellular biological research to provide the scientific foundation in support of hazard identification and risk assessment today.

Here at Public Health and Toxicology, we focus on publishing innovative international peer-reviewed research on all aspects of toxicology that can affect directly and indirectly the public from exposure to chemical and/or biological agents (environmental toxicology) and actions to protect public health and the environment through subsequent recommendations to reduce any resulting health effects (regulatory toxicology), including populationbased research and the evaluation of environmental risk throughout the lifespan including prenatal and postnatal development, childhood, adulthood and high-risk groups, and the impact on biological systems and the causes underlying the variability in susceptibility of people to exposures. Most importantly, Public Health and Toxicology is also highly interested in the recent real life risk simulation (RLRS) concept that plays a key role in chronic exposure paradigms.
Public Health and Toxicology is published by European Publishing, an Open Access publishing firm supported by the European Union Regional Development Fund, Smart Specialization strategy (RIS3) and based within the Science and Technology Park of Crete, Greece. The journal adheres to the COPE Code of Conduct and Best-Practice Guidelines for Journal Editors, and the ICMJE's Recommendations for the Conduct, Reporting, Editing and Publication of Scholarly Work in Medical Journals.

Due to recent public health emergencies, the journal also welcomes research on public health emergency preparedness related to environmental accidents and epidemics, such as the ongoing COVID-19 pandemic, including natural and man-made disasters, that assesses this exposure and outcome associations, from a public health toxicology perspective.

The need to enhance and further develop methods and approaches for evaluating toxicology issues cannot be overstated. Therefore, we welcome relevant manuscripts to Public Health and Toxicology that broaden these views and further enhance the discipline of Public Health and Toxicologgy.

CONFLICTS OF INTEREST

The authors have completed and submitted the ICMJE Form for Disclosure of Potential Conflicts of Interest and none was reported.

FUNDING

There was no source of funding for this research.

ETHICAL APPROVAL AND INFORMED CONSENT

Ethical approval and informed consent were not required for this study. 